\title{
Electronic Effects of Group Fragments on the XPS of Fe 2p and 3p Photoelectron Lines of Ferrocenyl-containing Chalcones
}

\author{
E. Erasmus* \\ Department of Chemistry, P.O. Box 339, University of the Free State, Bloemfontein, 9300, South Africa.
}

Received 2 November 2016, revised 13 April 2017, accepted 20 April 2017

\begin{abstract}
A series of ferrocenyl-containing chalcones, $\mathrm{Fc}-\mathrm{CO}-\mathrm{CH}=\mathrm{CH}-\mathrm{C}_{6} \mathrm{H}_{4} \mathrm{R}$, with the R-group on the para-position on the phenyl ring and $\mathrm{R}=\mathrm{OCH}_{3}(1), \mathrm{CH}_{3}(2), \mathrm{C}_{6} \mathrm{H}_{5}(3), t \mathrm{Bu}(4), \mathrm{H}(5), \mathrm{Br}(6)$ and $\mathrm{CF}_{3}(7)$ were subjected to an X-ray photoelectron spectroscopy (XPS) study. The linear relationships obtained between the Gordy-scale group electronegativity of molecular fragment $R, \chi_{R}$ and the maximum binding energies of the $\mathrm{Fe} 2 \mathrm{p}_{3 / 2}$ and the $\mathrm{Fe} 3 \mathrm{p}_{3 / 2}$ photoelectron lines, confirmed communication between the iron atom of the ferrocene moiety and the molecular fragments, $R$, of 1-7. These relationships illustrated that the influence of the electronic properties of the molecular fragments are more pronounced in the Fe 3 p photoelectron lines than in the Fe 2p photoelectron lines.
\end{abstract}

KEYWORDS

XPS, binding energy, ferrocene, chalcones, electronegativity.

\section{Introduction}

Chalcones are organic compounds with an enone backbone, containing aromatic end groups, and are one of the primary building blocks of flavonoids. ${ }^{1}$ In ferrocenyl-containing chalcones, one (or more) of the aromatic rings are replaced with a ferrocenyl group. ${ }^{2}$ The catalytic, ${ }^{3-5}$ electrochemical ${ }^{6-10}$ and structural properties, ${ }^{6,11,12}$ of ferrocene and its derivatives, like ferrocenyl-containing chalcones, have been studied with a variety of different techniques. However, characterization by means of X-ray photoelectron Spectroscopy (XPS) is unvisited for these complexes.

XPS is a very useful tool to determine elements present in a sample, the oxidation state of the elements and even the chemical environment which surrounds the element. In our ongoing study to determine relationships between group electronegativity and other physical properties of ferrocenylcontaining compounds, it has been found that group electronegativity influences not only the electrochemistry but also kinetics and NMR positions. ${ }^{6,8,13-20}$ Herewith we want to investigate whether the group electronegativity of the R-group's influence can be detected by the position of the binding energy of the iron in the ferrocenyl group.

In this study a variety of ferrocenyl-containing chalcones with the structure Fc-CO-CH=CH- $\mathrm{C}_{6} \mathrm{H}_{4} \mathrm{R}$, where $\mathrm{R}$ is in the para-position on the phenyl ring and $\mathrm{R}=\mathrm{OCH}_{3}(\mathbf{1}), \mathrm{CH}_{3}(2), \mathrm{C}_{6} \mathrm{H}_{5}$ (3), $t \mathrm{Bu}(4), \mathrm{H}(5), \mathrm{Br}(6)$ and $\mathrm{CF}_{3}(7)$, see Fig. 1, was subjected to $X$-ray photoelectron spectroscopy. The Fe $2 p$ and Fe $3 p$ photoelectron lines were measured and its binding energy positions were correlated against an assortment of other physical and calculated properties.

\section{Experimental}

\subsection{Chemicals and Instruments}

The ferrocenyl-containing chalcone derivatives 1-7 were synthesized and characterized according to published methods. ${ }^{6}$

*To whom correspondence should be addressed. E-mail: erasmuse@ ufs.ac.za

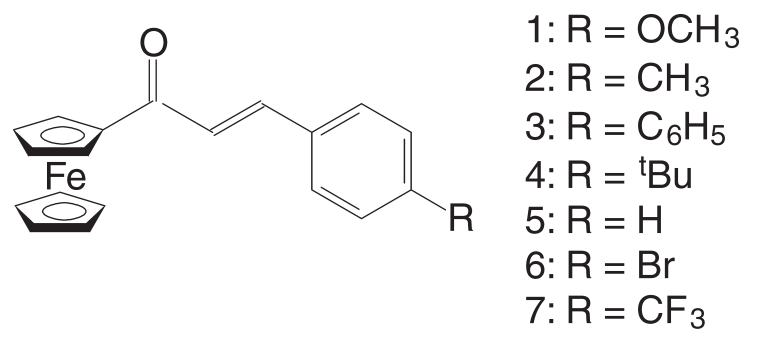

Figure 1 Structure of the ferrocenyl-containing chalcones investigated during this study.

All computational and electrochemical results presented here were taken from Ref. 6. XPS were recorded of neat powered samples which were held in place on the sample holder by means of carbon tape. To study the powered samples, the X-ray photoelectron spectroscopy (XPS) was conducted on a PHI 5000 versa probe spectrometer using monochromatic $\mathrm{Al} K_{\alpha}$ radiation ( $h v=1486.6 \mathrm{eV}$ ) generated by a $25 \mathrm{~W}, 15 \mathrm{kV}$ electron beam. For high-resolution spectra, the Hemispherical Analyzer pass energy was maintained at $93.90 \mathrm{eV}$. Measurements were performed using a $1 \mathrm{eV} /$ step binding energies for survey scans from 0 to $1400 \mathrm{eV}$, while a $0.1 \mathrm{eV} /$ step binding energy was used for the high-resolution spectra. The X-ray beam size used for the XPS measurements was $10 \mu \mathrm{m}$. The pressure during acquisition was less than $1.3 \times 10^{-9}$ Torr. All the absolute binding energies of the photoelectron spectra were corrected with C $1 \mathrm{~s}$ signal at $284.6 \mathrm{eV}$ (the lowest binding energy of the simulated adventitious C $1 \mathrm{~s}$ photoelectron line). ${ }^{21}$ The XPS data was analyzed utilizing Multipak version 8.2c computer software, ${ }^{22}$ and applying Gaussian-Lorentz fits (the Gaussian/Lorentz ratios were always $>95 \%$ ).

\section{Results and Discussion}

The systematic variation of the molecular fragment, $R$, in the para-position on the phenyl ring of the series of ferrocenylcontaining chalcones, $\mathrm{Fc}-\mathrm{CO}-\mathrm{CH}=\mathrm{CH}-\mathrm{C}_{6} \mathrm{H}_{4}-p-\mathrm{R}$, with $\mathrm{R}=$ 
$\mathrm{OCH}_{3}(1), \mathrm{CH}_{3}(2), \mathrm{C}_{6} \mathrm{H}_{5}(3), t \mathrm{Bu}(4), \mathrm{H}(5), \mathrm{Br}(6)$ and $\mathrm{CF}_{3}(7)$, allows for the investigation of the influence of the electronic properties of $\mathrm{R}$ on the binding energy of the photoelectron lines as detected by X-ray photoelectron spectroscopy (XPS). The differences in binding energies detected of the photoelectron lines will be related to the alterations in the electronic structure of the ferrocenyl-containing chalcones as well as DFT calculated parameter and other physical properties.

Firstly, the influence of the electronic properties of the different molecular fragments (electron-withdrawing and donating) on XPS measured binding energies of the Fe $2 p$ peaks of the ferrocenyl-containing chalcones will be described and this concept will then be expanded to the Fe 3p peaks.

The Fe $2 p_{1 / 2}$ and $F e 2 p_{3 / 2}$ photoelectron lines, as measured by XPS of the $\mathrm{Fe}^{2+}$ ions of the ferrocenyl-containing chalcones (1-7) gave sharp well-defined single peaks, with some showing a small unsymmetrical tail toward the high energy side (Fig. 2, left). This tail is normal for metals of the first row of the transition metals. . $32,24,26^{2}$

Naumkin et al. reported the deconvolution of Fe(II) complexes with multiplet splitting peaks which was attributed to different non-equivalent states of the $\mathrm{Fe}(\mathrm{II}){ }^{25}$ However, since the main

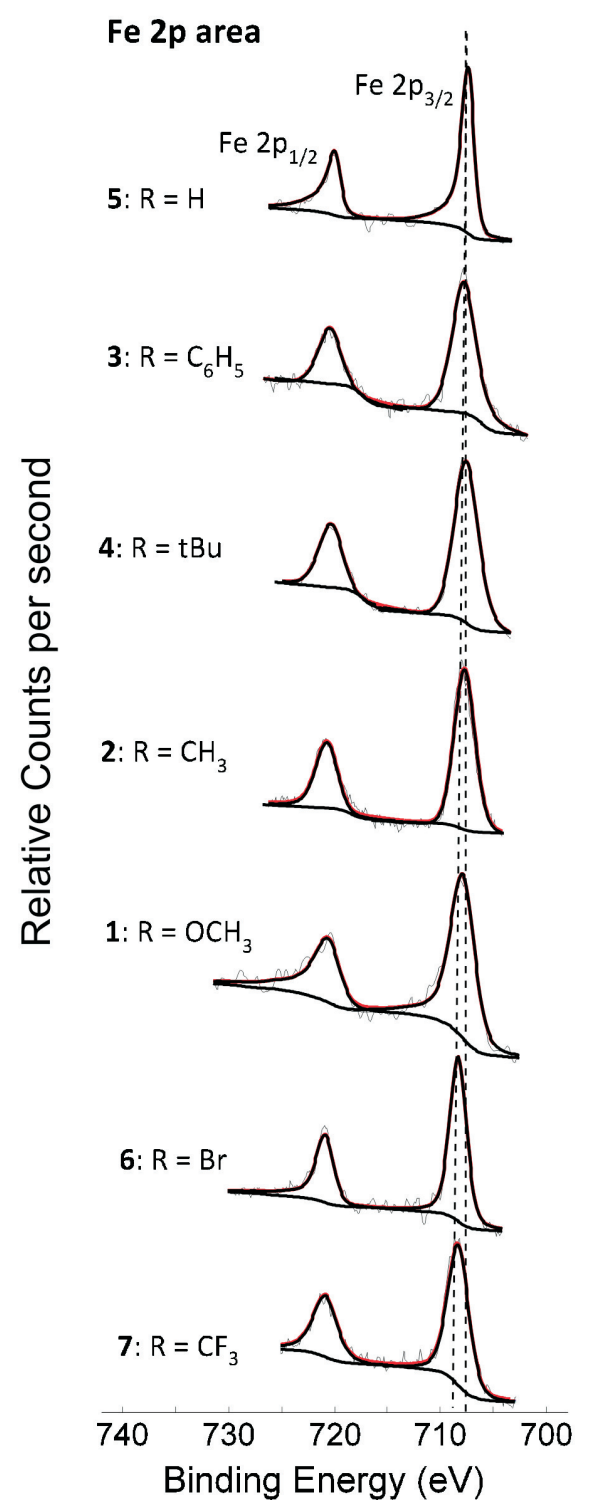

purpose of this article is the comparison of the maximum binding energy of the Fe $2 p$ envelopes with different physical properties of the R-groups, the photoelectron lines will not be deconvoluted into multiplet peaks. During the fitting of these $\mathrm{Fe} 2 \mathrm{p}_{1 / 2}$ and $\mathrm{Fe} 2 \mathrm{p}_{3 / 2}$ photoelectron lines, a single asymmetric Gaussian peak with a full width at half maximum (FWHM) of ca. $1.8 \mathrm{eV}$ was utilized giving chi-square values between 0.5 and 1.1. The goodness of the fit as well as the sharpness of the peaks verifies that only one iron species is present in the ferrocenylcontaining chalcone..$^{26}$ The sharpness of the peaks also indicates that the chalcones are stable under irradiation with X-ray and did not decompose during the experiment. The asymmetric index, $\alpha$, (which is the ratio of the half width at half maximum on the high energy side to the half width at half maximum on the low energy side) of the Fe $2 p_{1 / 2}$ and $\mathrm{Fe} 2 \mathrm{p}_{3 / 2}$ photoelectron peaks being 1.25 and 1.3, respectively. These values are typical for transition metal ions of the first row. ${ }^{27}$

The iron in the ferrocenyl groups have equal $3 \mathrm{~d}$ subshell population $\left(3 \mathrm{~d}^{6}\right)$ and therefore the iron atoms is a low-spin Fe(II) species. Therefore, during the fitting of the Fe $2 p$ and Fe $3 p$ peaks there is no need to take any final-state effects like multiplet splitting and shake-up peaks into account.

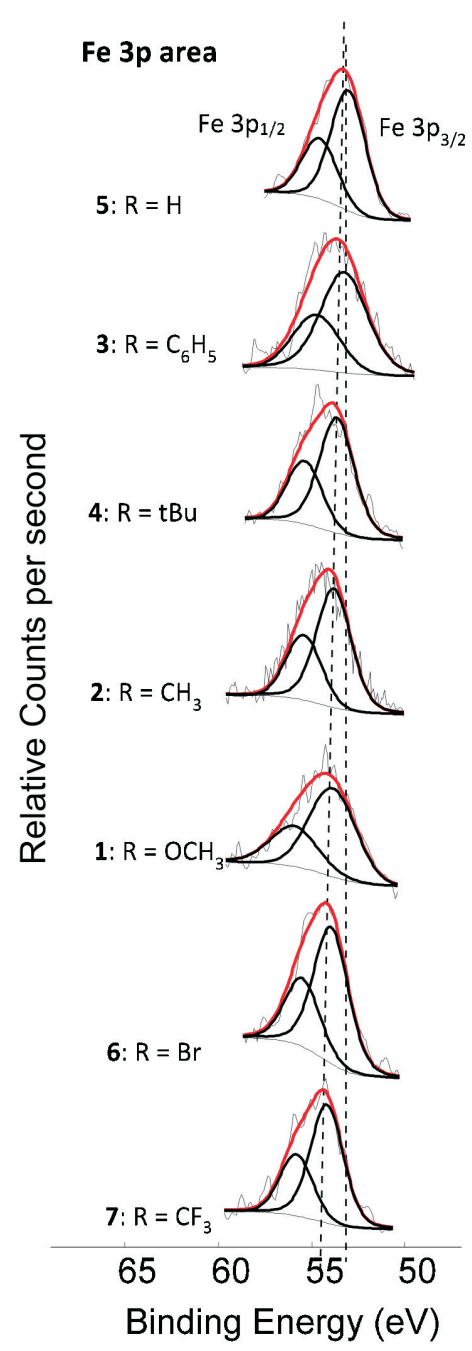

Figure 2 Comparative XPS spectra (left) of the Fe $2 p$ area of ferrocenyl-containing chalcones, 1-7, and (right) of the Fe $3 p$ area ferrocenyl-containing chalcones, 1-7. 
Table 1 Binding energies of the maximum binding energy of the $\mathrm{Fe} 2 \mathrm{p}_{1 / 2}$, Fe $2 \mathrm{p}_{3 / 2}$, Fe $3 \mathrm{p}_{1 / 2}$ and $\mathrm{Fe} 3 \mathrm{p}_{3 / 2}$ photoelectron lines, the spin-orbit splitting of maximum binding energies of the photoelectron lines, $\Delta\left(\mathrm{BE}_{\mathrm{p} 1 / 2 \mathrm{-p} / 2 / 2}\right)$, Gordy-scale group electronegativity of the R-groups, $\chi_{\mathrm{R}}$, as well as the Hammett constants, $\mathrm{s}_{\mathrm{R}}$.

\begin{tabular}{|c|c|c|c|c|c|c|c|c|}
\hline No. & $\mathrm{Fe} 2 \mathrm{p}_{3 / 2}(\mathrm{eV})$ & $\mathrm{Fe} 2 \mathrm{p}_{1 / 2}(\mathrm{eV})$ & $\Delta\left(\mathrm{BE}_{2 \mathrm{p}}\right)(\mathrm{eV})$ & $\mathrm{Fe} 3 \mathrm{p}_{3 / 2}(\mathrm{eV})$ & $\mathrm{Fe} 3 \mathrm{p}_{1 / 2}(\mathrm{eV})$ & $\Delta\left(\mathrm{BE}_{3 \mathrm{p}}\right)(\mathrm{eV})$ & $\begin{array}{c}\chi_{\mathrm{R}} \\
\text { Gordy }{ }^{a}\end{array}$ & $\begin{array}{c}\sigma_{\mathrm{R}} \\
\text { Hammett }^{\mathrm{a}}\end{array}$ \\
\hline $1: \mathrm{R}=\mathrm{OCH}_{3}$ & 707.83 & 720.56 & 12.73 & 53.99 & 55.52 & 1.53 & 2.64 & -0.268 \\
\hline $2: \mathrm{R}=\mathrm{CH}_{3}$ & 707.64 & 720.29 & 12.65 & 53.78 & 55.38 & 1.60 & 2.34 & -0.170 \\
\hline 3: $\mathrm{R}=\mathrm{C}_{6} \mathrm{H}_{5}$ & 707.54 & 720.15 & 12.61 & 53.66 & 55.34 & 1.68 & 2.21 & -0.010 \\
\hline $4: \mathrm{R}=t \mathrm{Bu}$ & 707.56 & 720.19 & 12.63 & 53.73 & 55.38 & 1.65 & 2.27 & -0.100 \\
\hline $5: \mathrm{R}=\mathrm{H}$ & 707.53 & 720.13 & 12.60 & 53.60 & 55.36 & 1.76 & 2.13 & 0.000 \\
\hline $6: \mathrm{R}=\mathrm{Br}$ & 707.86 & 720.59 & 12.73 & 54.19 & 55.75 & 1.56 & 2.70 & 0.232 \\
\hline $7: \mathrm{R}=p-\mathrm{CF}_{3}$ & 708.05 & 720.85 & 12.80 & 54.51 & 56.04 & 1.53 & 3.01 & 0.540 \\
\hline $8: \mathrm{R}=m-\mathrm{CF}_{3}$ & 707.79 & 720.20 & 12.46 & 53.93 & 55.45 & 1.52 & 3.01 & - \\
\hline $9: \mathrm{R}=0-\mathrm{CF}_{3}$ & 707.70 & 720.16 & 12.41 & 53.92 & 55.45 & 1.53 & 3.01 & - \\
\hline
\end{tabular}

${ }^{\text {a }}$ Data obtained from reference 18.

The maximum binding energy of the $\mathrm{Fe} 2 \mathrm{p}_{3 / 2}$ photoelectron lines of 1-7 was located between 707.53 to $708.05 \mathrm{eV}$ (see Table 1 ). The change in position of the binding energy is caused by the inductive electronic effects of the molecular fragments, $R$. This $0.52 \mathrm{eV}$ binding energy range, is considered large since a $1 \mathrm{eV}$ binding energy change is associated with a full iron redox state change from $\mathrm{Fe}^{2+}$ to $\mathrm{Fe}^{3+}$. Also, this range of binding energies are larger than the binding energy range of $0.34 \mathrm{eV}$ which was found for the $\mathrm{Fe} 2 \mathrm{p}_{3 / 2}$ photoelectron lines of $\mathrm{Mn}$ (B-diketonato) ${ }_{3}$ complexes. ${ }^{28,29}$

The binding energies obtained for the Fe $2 \mathrm{p}_{3 / 2}$ photoelectron lines of 1-7 correlates very well with other Fe(II) species, iron disphosphide ${ }^{30}$ bis(cyclopentadenyl)iron, ${ }^{31}$ and the ferrocenylgroup in Mn(B-diketonato) ${ }_{3}{ }^{28,29}$ all located at $c a .707 .7 \mathrm{eV}$. However, the Fe $2 p$ of the ferrocenyl-containing chalcones is located at lower binding energy compared to a ferrocenyl linked via an aminoalkyl silane onto silicon $(709.7 \mathrm{eV}){ }^{32}$

A spin-orbit splitting of $c a .13 .5 \mathrm{eV}$ was obtained between the $\mathrm{Fe} 2 \mathrm{p}_{3 / 2}$ and $\mathrm{Fe} 2 \mathrm{p}_{1 / 2}$ photoelectron lines, depending on the molecular fragment, R (see Fig. 3 middle and Table 1).

The only other photoelectron lines which could be detected in the XPS of 1-7 are carbon (with a maximum binding energy at ca. $284.6 \mathrm{eV}$ ) and oxygen (with a maximum binding energy at ca. $528.8 \mathrm{eV}$ ). The ferrocenyl-containing chalcones, 6-7 also displayed bromine at $69.6 \mathrm{eV}$ and fluorine at $687.8 \mathrm{eV}$, respectively. The correct atomic percentage ratio of 1:1 between the Fe $2 p$ peak and the Br $3 d$ peak, within experimental error, was obtained for 6 (experimental ratio is 1:1.1). For 7 the correct atomic percentage ratio of 1:3.2 was experimentally obtained between the Fe $2 p$ and the F 2 s (theoretical value 1:3). All the detected photoelectron lines were charge corrected against $C 1 \mathrm{~s}$ at $284.6 \mathrm{eV}$ (the lowest binding energy of the simulated adventitious $\mathrm{C} 1 \mathrm{~s}$ photoelectron line).

The substructure of the carbon photoelectron line was fitted with separate peaks located at $292.8 \mathrm{eV}$ (representing the $\mathrm{C}-\mathrm{F}$ ), $286.7 \mathrm{eV}$ (representing the $\mathrm{C}=\mathrm{O}$ ) and $284.6 \mathrm{eV}$ (representing the all the other carbon involved in $\mathrm{C}-\mathrm{C}$ bonding) allocated to the ferrocenyl-chalcone, 7 was used as an example, in the expected ratio of 1:1:18, while the additional peak detected at $288.4 \mathrm{eV}$ (representing the $\mathrm{O}=\underline{\mathrm{C}}=\mathrm{O}$ ), $286.6 \mathrm{eV}$ (representing the $\mathrm{C}=\mathrm{O}$ ) and $284.6 \mathrm{eV}$ (representing the all the other carbon involved in C-C bonding) comes from the adventitious carbon always present on all samples (see Fig. S1 for the C $1 \mathrm{~s}$ are of 7 in the Supplementary Information).

Published results indicate that the Gordy-scale group electronegativity, $\chi_{\mathrm{R}}{ }^{33}$ of the molecular fragments, $\mathrm{R}$, can influence the physical properties of a compound like reaction kinetics, electrochemistry and NMR peak positions. ${ }^{6,7,13-20}$ An increase in the Gordy-scale group electronegativity, $\chi_{\mathrm{R}}$, of the molecular fragment, $R$, causes an increase in the binding energy of the Fe $2 p_{3 / 2}$ photoelectron line, as well as an increase in the spin-orbit splitting $\left(\Delta \mathrm{BE}_{2 \mathrm{p} 1 / 2-2 \mathrm{p} / 2 / 2}\right)$ between the binding energy of the Fe $2 \mathrm{p}_{1 / 2}$ and $\mathrm{Fe} 2 \mathrm{p}_{3 / 2}$ photoelectron lines (see Fig. 3 left and middle as well as Table 1). As the Gordy-scale group electronegativity, $\chi_{R}$, increases, more electron density is pulled towards the stronger electron-withdrawing molecular fragments. This causes the $\mathrm{Fe}^{2+}$ ions to have less electron density around it. Therefore, the $\mathrm{Fe}^{2+}$ ion binds stronger to its own electrons, hence the increased binding energy. The linear relationships obtained between the binding energy (BE) of the iron Fe $2 p_{3 / 2}$ photoelectron lines, the
$\mathrm{Fe} 2 \mathrm{p}_{3 / 2}$

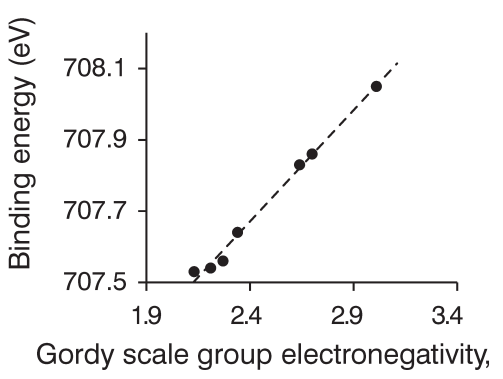

$\chi_{\mathrm{R}}$
$\mathrm{Fe} 2 \mathrm{p}$

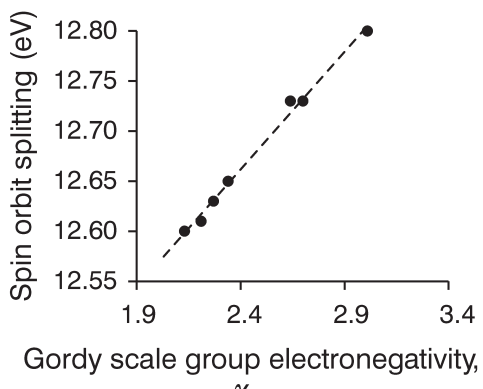

$\chi_{\mathrm{R}}$
$\mathrm{Fe} 3 \mathrm{p}_{3 / 2}$

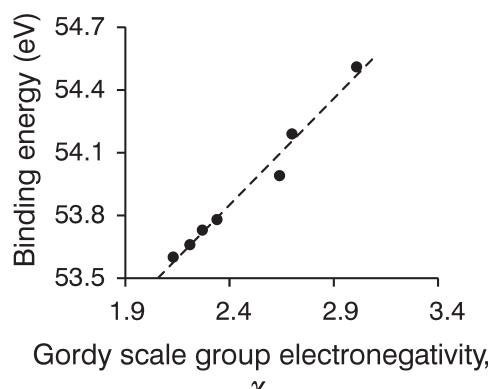

$\chi_{\mathrm{R}}$

Figure 3 Left: relationship between binding energy of the Fe $2 p_{3 / 2}$ photoelectron line and Gordy-scale group electronegativities, $\chi_{\mathrm{R}}$, of the molecular fragments, R. Middle: relationship between the spin-orbit splitting $\left(\Delta B E_{2 p 1 / 2-2 p 3 / 2}\right)$ of the binding energy of the Fe $2 p_{1 / 2}$ and Fe $2 p_{3 / 2}$ photoelectron lines and Gordy-scale group electronegativities, $\chi_{\mathrm{R}}$, of the molecular fragments, R. Right: relationship between binding energy of the Fe $3 p_{3 / 2}$ photoelectron line and Gordy-scale group electronegativities, $\chi_{\mathrm{R}}$, of the molecular fragments, $\mathrm{R}$. 
spin-orbit splitting $\left(\Delta B E_{2 p 1 / 2-2 p 3 / 2}\right)$ and $\chi_{\mathrm{R}}$ (Fig. 3 left and middle) fits the equations:

$$
\begin{aligned}
& \mathrm{BE}=0.62\left(\chi_{\mathrm{R}}\right)+706.17 ; \mathrm{R}^{2}=0.99 \\
& \Delta \mathrm{BE}_{2 \mathrm{p} 1 / 2 \mathrm{-2} 3 / 2}=0.24\left(\chi_{\mathrm{R}}\right)+12.10 ; \mathrm{R}^{2}=0.99
\end{aligned}
$$

The $\mathrm{Fe} 3 \mathrm{p}_{1 / 2}$ and $\mathrm{Fe} 3 \mathrm{p}_{3 / 2}$ photoelectron lines of these ferrocenyl-containing chalcone $\mathbf{1 - 7}$, is represented by a single broad peak, with no definite shape showing the separation between the $3 p_{1 / 2}$ and $3 p_{3 / 2}$ lines (see Fig. 2). This, however, is normally the case for Fe $3 p$ peaks since the spin-orbit splitting between the $\mathrm{Fe} 3 \mathrm{p}_{1 / 2}$ and $\mathrm{Fe} 3 \mathrm{p}_{3 / 2}$ photoelectron lines is less than $2 \mathrm{eV}$.

Compared to the Fe $2 p$ photoelectron lines, also only one Gaussian peak was fitted for the Fe 3p photoelectron lines of 1-7, with a FWHM ranging between 2.2 and $2.9 \mathrm{eV}$. The asymmetric index, $\alpha$, of the $\mathrm{Fe} 3 \mathrm{p}_{1 / 2}$ and $\mathrm{Fe} 3 \mathrm{p}_{3 / 2}$ photoelectron peaks are both 1.1. The maximum binding energy for the $\mathrm{Fe} 3 \mathrm{p}_{3 / 2}$ photoelectron lines was detected at $c a .53 .9 \mathrm{eV}$ (see Table 1), with a spin-orbit splitting of $c a$. $1.6 \mathrm{eV}$ between the $\mathrm{Fe} 3 \mathrm{p}_{3 / 2}$ and $\mathrm{Fe} 3 \mathrm{p}_{1 / 2}$ photoelectron lines.

Similar to what was found for the $\mathrm{Fe} 2 \mathrm{p}_{3 / 2}$ photoelectron lines, an increase in molecular fragment's Gordy-scale group electronegativity led to an increase in the maximum binding energy of the $\mathrm{Fe} 3 \mathrm{p}_{3 / 2}$ photoelectron lines (Fig. 3, right and Table 1). The maximum binding energy of the $\mathrm{Fe} 3 \mathrm{p}_{3 / 2}$ photoelectron lines is located in the range $53.6-54.5 \mathrm{eV}$. This is a $0.9 \mathrm{eV}$ span, obtained for $\mathrm{Fe}^{2+}$ of the ferrocenyl fragment within the chalcone. The binding energy span for the $\mathrm{Fe} 3 \mathrm{p}_{3 / 2}$ photoelectron lines is almost equivalent to an entire oxidation state change, which is normally $1 \mathrm{eV}$. Compared to the $\mathrm{Fe} 2 \mathrm{p}_{3 / 2}$ photoelectron lines which had a binding energy span of $0.53 \mathrm{eV}$, the Fe $3 p_{3 / 2}$ photoelectron lines has a $0.9 \mathrm{eV}$ binding energy span, almost double that of the $\mathrm{Fe} 3 \mathrm{p}_{3 / 2}$ photoelectron lines. Also, the slope of the equation that fits the relationships between the binding energy of phototelectron lines and the Gordy-scale group electronegativity of the $\mathrm{Fe} 3 \mathrm{p}_{3 / 2}$ which is 1.02 (Equation 3 ) is much steeper than the Fe $3 p_{3 / 2}$ which is 0.62 (Equation 1 ). This clearly shows that the electrons located in higher energy level orbitals experience the influence of the electronic properties of the changing molecular fragments more intense.

\section{Fe $2 p$ area}

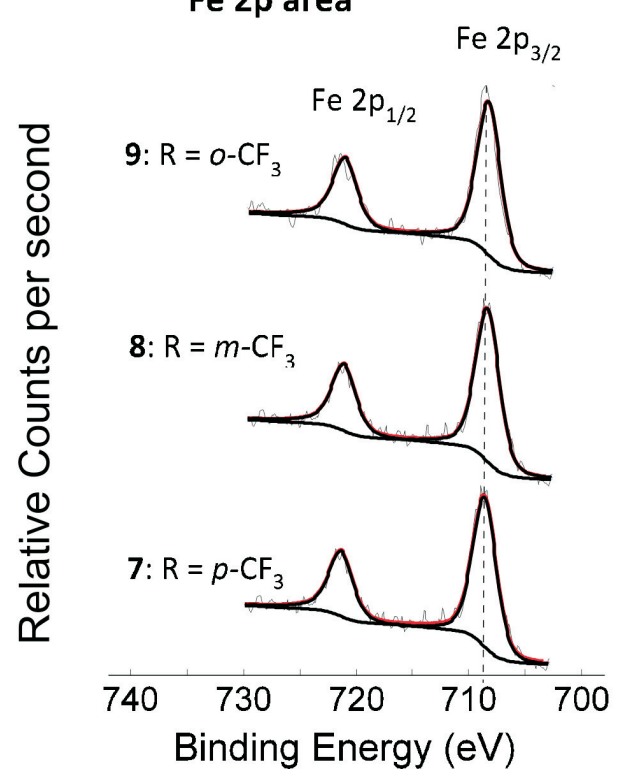

The linear relationships obtained between the binding energy (BE) of the iron $\mathrm{Fe} 3 \mathrm{p}_{3 / 2}$ photoelectron lines and the Gordy-scale group electronegativity of the various molecular fragments, $\chi_{R}$ (Fig. 3, right) is described by the equation:

$$
\mathrm{BE}=1.02 \chi_{\mathrm{R}}+51.40 ; \mathrm{R}^{2}=0.98
$$

The linearity of the relationships between Gordy-scale group electronegativities of the molecular fragment, $\chi_{\mathrm{R}}$, and the different binding energies of both the Fe $2 \mathrm{p}_{3 / 2}$ and $\mathrm{Fe} 3 \mathrm{p}_{3 / 2}$ photoelectron lines, shows that the electronic communication through the bonds from the molecular fragment, $\mathrm{R}$, to the $\mathrm{Fe}^{2+}$ in the ferrocenyl-containing chalcones, $\mathbf{1 - 7}$, is very good.

The position of the molecular fragment on the phenyl was varied (to be either ortho, meta or para, see Fig. 4) to detect if the position also makes a different in the measured binding energy of the Fe $2 \mathrm{p}$ and $\mathrm{Fe} 3 \mathrm{p}$ photoelectron lines.

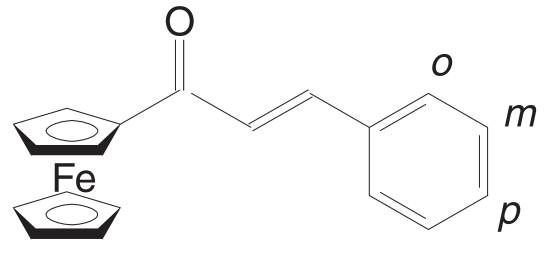

$$
\mathrm{CF}_{3} \text { in either } o(9), m(8) \text { or } p(7) \text { position }
$$

Figure 4 Structure of the ferrocenyl-containing chalcone with a $\mathrm{CF}_{3}$ group on either the ortho $(o)$, meta $(m)$ or para $(p)$ position on the phenyl ring.

The comparative XPS spectra of the Fe $2 p$ and $\mathrm{Fe} 3 p$ areas of the ferrocenyl-containing chalcones, 7-9, with $\mathrm{CF}_{3}$ containing chalcone at different position on the phenyl ring are shown in Fig. 5. As the $\mathrm{CF}_{3}$ fragment is moved from ortho to meta to para, thus moving further away from the chalcone backbone, the binding energy of the $\mathrm{Fe} 2 \mathrm{p}_{3 / 2}$ and $\mathrm{Fe} 3 \mathrm{p}_{3 / 2}$ photoelectron lines increases (see Table 1). A binding energy difference of $0.35 \mathrm{eV}$ for the Fe $2 p_{3 / 2}$ and $0.59 \mathrm{eV}$ for the Fe $3 p_{3 / 2}$ photoelectron lines was found between the ortho and the para positions, respectively. This clearly shows that the position on the phenyl ring also has a pronounced effect on the electronic structure of the ferrocenylcontaining chalcones.

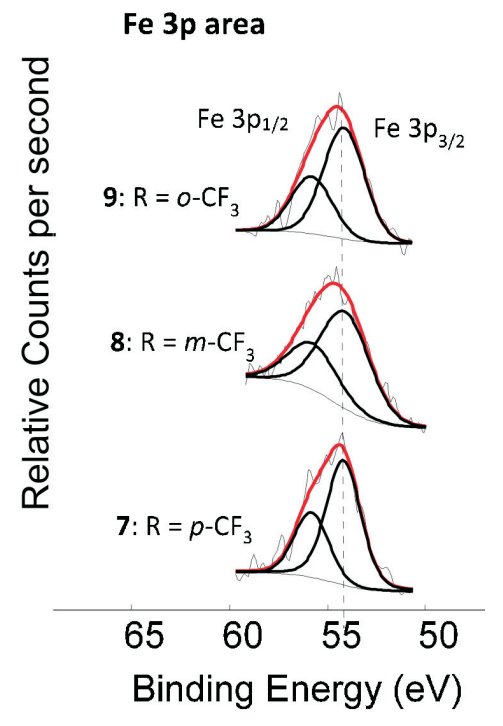

Figure 5 Comparative XPS spectra of the Fe 2p area (left) of ferrocenyl-containing chalcones, 7-9, and of the Fe 3p area (right) ferrocenyl-containing chalcones,7-9. 


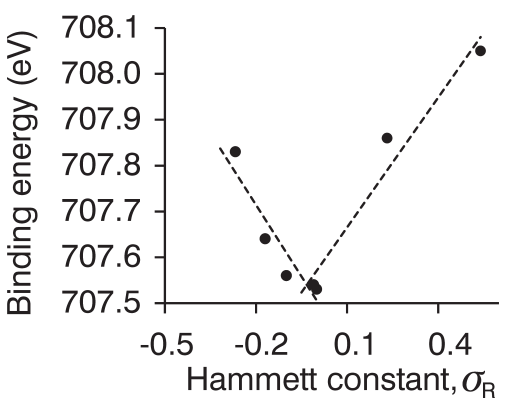

Figure 6 Relationship between binding energy of the $\mathrm{Fe} 2 \mathrm{p}_{3 / 2}$ photoelectron line and the Hammett constant, $\sigma_{R^{\prime}}$ of the molecular fragments, $\mathrm{R}$.

The relationship of the binding energies of both the Fe $2 p_{3 / 2}$ and Fe $3 p_{3 / 2}$ photoelectron lines of the ferrocenyl-containing chalcones versus the Hammett constants revealed a V-shaped correlation (see Fig. 6). The halogen-containing chalcones (6-7) forms the one linear relationship, while the other linear relationship is formed by the non-halogen containing chalcones (1-5). The ferrocenyl-containing chalcone, 5 , where $\mathrm{R}=\mathrm{H}$, forms part of both these correlations and is at the tip of the V.

The linear relationships obtained between the binding energy (BE) of the iron $\mathrm{Fe} 3 \mathrm{p}_{3 / 2}$ photoelectron lines and the Hammett constants of the R-fragments (Fig. 6) are described by the equations:

For the halogen-containing chalcones $(\mathbf{1}, \mathbf{6}-\mathbf{7})$

$\mathrm{BE}=0.95 \sigma_{\mathrm{R}}+707.57 ; \mathrm{R}^{2}=0.95$

For the non-halogen containing chalcones (1-5)

$\mathrm{BE}=-1.04 \sigma_{\mathrm{R}}+707.51 ; \mathrm{R}^{2}=0.88$

The V-shape correlation observed is similar to the correlation observed between the reduction potential and the Gordy group electronegativity, $\chi_{R}$, previously reported. ${ }^{6}$

A linear correlation was obtained between the Gordy group electronegativity, $\chi_{R}$ and the binding energies of the Fe $2 p$ and Fe $3 p$ photoelectron lines while a V-shape correlation was obtained when using the Hammett constants.

The linear relationship obtained with the Gordy group electronegativity, $\chi_{R}$ and the binding energies of the Fe $2 p$ and Fe $3 p$ photoelectron lines was expected since there are many reports on the binding energy's linear dependence on electronegativity. ${ }^{16,17,28,34-37}$ On account of the V-shaped curve found between the Gordy group electronegativity, $\chi_{R^{\prime}}$ and the Hammett constants of different R-groups, ${ }^{6}$ the V-shaped curve found between the Hammett constants and the binding energies of the Fe $2 p$ and Fe $3 p$ photoelectron lines was not unexpected. V-shape correlations obtained with Hammett constants are not uncommon, there are many reports of V- or U-shaped curves linking Hammett constant with other physical parameters, including kinetic constants and degree of substitution. ${ }^{38-41}$

The Hammett constant is a value composing of a mixture of electronic effects including polar and resonance effects. ${ }^{42}$ Since polar effects which is incorporated in the Hammett constant represents a similar effects as electronegativity of the Gordyscale group electronegativity, it is proposed that the V-shape presumably comes from the resonance effect incorporated in the Hammett constant. This could possibly explain the difference between the halogen-containing chalones (electron-withdrawing R-groups) and the non-halogen-containing chalcones (electron-donating). When a core electron is emitted due to photoionization, the chalcone will try to stabilize this newly formed positive species. The type of stabilization will be dependent on the different R-groups. The halogen-containing chalcones (6-7), which has an electron-withdrawing R-group has can form a stabilized zwitterion through an inductive effect. While the non-halogen-containing chalcones (1-5), which has an electrondonating R-groups can form stabilized zwitterions through a resonance effect (see Ref. 6 for the proposed structures).

The V-shape correlation that was obtained highlights the changeover in stabilization mechanism for the chalcones having either electron-donating or electron-withdrawing R-groups and it distinguished between polar (electronegativity) and resonance effects.

\section{Conclusion}

The changes in the binding energy obtained from the Fe $2 p$ and $\mathrm{Fe} 3 \mathrm{p}$ photoelectron lines upon substituting the group fragment $R$ was investigated. The influence of the changing fragment $\mathrm{R}$ on the binding energy of the Fe $3 p$ photoelectron lines (binding energy range $=0.90 \mathrm{eV}$ ) was found to be more pronounce than what was found for the binding energy of the $\mathrm{Fe} 2 \mathrm{p}$ photoelectron lines (binding energy range $=0.52 \mathrm{eV}$ ). A linear relationship was obtained between the Gordy-scale group electronegativities, $\chi_{R^{\prime}}$ of the molecular fragments, $R$, and the binding energies of the Fe $2 p_{3 / 2}$, Fe $3 p_{3 / 2}$ and spin-orbit splitting $\left(\Delta \mathrm{BE}_{2 \mathrm{p} 1 / 2-2 \mathrm{p} / 2 / 2}\right)$ of the binding energy of the $\mathrm{Fe} 2 \mathrm{p}_{1 / 2}$ and $\mathrm{Fe} 2 \mathrm{p}_{3 / 2}$ photoelectron lines. In contrast to this, a V-shape relationship was found between the binding energy of the $\mathrm{Fe} 2 \mathrm{p}_{3 / 2}, \mathrm{Fe} 3 \mathrm{p}_{3 / 2}$ photoelectron lines and the Hammett constants of the R-groups. This V-shape correlation could possibly be attributed to the different forms of stabilization of zwitterion, for electron-withdrawing R-groups stabilization occurs through an inductive effect, while for electron-donating R-groups stabilization occurs through a resonance effect. The position of the molecular fragment $\mathrm{R}$ with in the phenyl ring also has a pronounce effect on the binding energy, a binding energy range of $0.35 \mathrm{eV}$ for the $\mathrm{Fe} 2 \mathrm{p}_{3 / 2}$ and $0.59 \mathrm{eV}$ for the $\mathrm{Fe} 3 \mathrm{p}_{3 / 2}$ photoelectron lines was found between the ortho and the para positions, respectively.

\section{Acknowledgements}

The author acknowledges financial support from the NRF, SASOL and the UFS during the course of this study.

\section{References and Notes}

1 Z. Ratkovic, Z.D. Juranic, T. Stanojkovic, D. Manojlovic, R.D. Vukicevic, N. Radulovic and M.D. Joksovic, Synthesis, characterization, electrochemical studies and antitumor activity of some new chalcone analogues containing ferrocenyl pyrazole moiety, Bioorg. Chem. 2010, 38, 26-32.

2 V. Zsoldos-Mady, A. Csampai, R. Szabo, E. Maszaros-Alapi, J. Pasztor, F. Hudecz and P. Sohar, Synthesis, structure, and in vitro antitumor activity of some glycoside derivatives of ferrocenyl-chalcones and ferrocenyl-pyrazolines, Chem. Med. Chem., 2006, 1, 1119-1125.

3 A. Togni, Ferrocenes: Homogeneous Catalysis/Organic Synthesis/Materials Science, Wiley-VCH, Weinheim, Germany, 1995.

4 C. Morari, I. Rungger, A.R. Rocha, S. Sanvito, S. Melinte and G.M. Rignanese, Electronic transport properties of 1, 1'-ferrocene dicarboxylic acid linked to Al (111) electrodes, ACSNano, 2009, 3, 4137-4143.

5 Timothy J. Gardner, C. Daniel Frisbie and Mark S. Wrighton, Systems for orthogonal self-assembly of electroactive monolayers on Au and ITO: an approach to molecular electronics, J. Am. Chem. Soc., 1995, 117, 6927-6933.

6 T.J. Muller, J. Conradie and E. Erasmus, A spectroscopic, electrochemical and DFT study of para-substituted ferrocene-containing chalcone derivatives: structure of $\mathrm{FcCOCHCH}\left(\mathrm{p}^{-}{ }^{\mathrm{B}} \mathrm{BuC}_{6} \mathrm{H}_{4}\right)$, Polyhedron, 2012, 33, 257-266.

7 A. Hildebrandt, T. Ruffer, E. Erasmus, J.C. Swarts and H. Lang, A star-shaped supercrowded 2,3,4,5-tetraferrocenylthiophene: synthesis, solid-state structure, and electrochemistry, Organomet., 2010, 29, 4900-4905. 
8 E. Erasmus, J. Conradie, A. Muller and J.C. Swarts, Synthesis, crystal structure and electrochemistry of tetrahedral mono- $\beta$-diketonato titanocenyl complexes, Inorg. Chim. Acta, 2007, 360, 2277-2283.

9 A. Auger and J.C. Swarts, Remarkable isolation, structural characterisation and electrochemistry of unexpected scrambling analogues of 5-ferrocenyl-10,20-diphenylporphyrin, Organomet., 2007, 26, 102-109.

10 J. Conradie and J.C. Swarts, Relationship between electrochemical potentials and substitution reaction rates of ferrocenecontaining $\beta$-diketonato rhodium(I) complexes; cytotoxicity of [Rh(FcCOCHCOPh)(cod)], Dalton Trans., 2011, 40, 5844-5851.

11 J.J.C. Erasmus, G.J. Lamprecht, J.C. Swarts, A. Roodt and A. Oskarsson, (E)-1,3-Diferrocenyl-2-buten-1-one-water (4/1), Acto Cryst., 1996, C52, 3000-3002.

12 W.C. du Plessis, J.J.C. Erasmus, G.J. Lamprecht, J. Conradie, T.S Cameron, M.A.S. Aquino and J.C. Swarts, Cyclic voltammetry of ferrocene-containing $\beta$-diketones as a tool to obtain group electronegativities. The structure of 3-ferrocenoyl-1,1,1-trifluoro-2 hydroxyprop-2-ene, Can. J. Chem., 1999, 77, 378-386.

13 E. Erasmus, Ferrocene- and ruthenocene-containing chalcones: a spectroscopic and electrochemical study, Inorg. Chim. Acta, 2011, 378, 95-101.

14 E. Erasmus and J.C. Swarts, Intramolecular communication and electrochemical observation of the 17-electron ruthenocenium cation in fluorinated ruthenocene-containing $\beta$-diketones; polymorphism of $\mathrm{C}_{10} \mathrm{H}_{21}$ and $\mathrm{C}_{10} \mathrm{~F}_{21}$ derivatives, New. J. Chem., 2013, 37, 2862-2873.

15 E. Erasmus, Synthesis and unexpected electrochemical reaction of p-substituted phenyl diphenylphosphinites, J. Electroanal. Chem., 2014, 727, 1-7.

16 M.M. Conradie, J. Conradie and E. Erasmus, Immobilisation of iron tris( $\beta$-diketonates) on a two-dimensional flat amine functionalised silicon wafer: a catalytic study of the formation of urethane, from ethanol and a diisocyanate derivative, Polyhedron, 2014, 79, 52-59.

17 E. Erasmus, Synthesis and electrochemistry of p-substituted phenyl diphenylphosphinite rhodium(I) complexes, Polyhedon, 2016, 106, $18-26$.

$18 \mathrm{~J}$. Conradie, Density functional theory calculations of Rh- $\beta$-diketonato complexes, Dalton Trans., 2015, 44, 1503-1515.

19 M.M. Conradie and J. Conradie, Electrochemical behaviour of Tris ( $\beta$-diketonato) iron (III) complexes: A DFT and experimental study, Electrochim. Acta, 2015, 152, 512-519.

20 R. Freitag and J. Conradie, Electrochemical and Computational Chemistry Study of $\mathrm{Mn}(\beta \text {-diketonato })_{3}$ complexes, Electrochim. Acta, 2015, 158, 418-426.

21 F. Moulder, W.F. Stickle, P.E. Sobol and K.D. Bomben, Handbook of X-ray Photoelectron Spectroscopy: a Reference book of Standard Spectra for Identification and Interpretation of XPS Data, ULVAC-PHI, Inc., Enzo, Chigasaki, Japan, 1995.

22 F. Moulder, W.F. Stickle, P.E. Sobol and K.D. Bomben, Handbook of X-ray Photo- 367 Electron Spectroscopy, ULVAC-PHI, Inc., 370 Enzo, Chigasaki 253-8522, Japan, 1995.

23 L. Marchetti, F. Miserque, S. Perrin and M. Pijolat, XPS study of Ni-base alloys oxide films formed in primary conditions of pressurized water reactor, Surface and Interface Analysis, Wiley-Blackwell, 2015, 47(5), 632-642.

24 A.P. Grosvenor, B.A. Kobe, M.C. Biesinger and N.S. McIntyre, Investigation of multiplet splitting of Fe 2p XPS spectra and bonding in iron compounds, Surf. Interf. Sci., 2004, 36, 1564-1574.

25 A.V. Naumkin, T.M. Ivanova, A.V. Schukarev, A.A. Sidrov, M.A Kiskin, V.M. Novotortsev and I.L. Eremenko, X-ray photoelectron spectra of iron trimethylacetate complexes, Russ. J. Inorg. Chem., 2008, 53, 1614-1620.

26 M.C. Biesinger, B.P. Payne, A.P. Grosvenor, L.W.M. Lau, A.R. Gerson and St.C.C. Smart, X-ray photoelectron spectroscopic chemical state quantification of mixed nickel metal, oxide and hydroxide systems, Appl. Surf. Sci., 2011, 257, 2717-2730.
27 S.P. Kowalczyyk, L.Ley, F.R. McFeely and D.A. Shirley, Multiplet splitting of the manganese $2 \mathrm{p}$ and $3 \mathrm{p}$ levels in $\mathrm{MnF}_{2}$ single crystals, Phys. Rev. B, 1975, 11, 1721-1727.

28 B.E. Buitendach, E. Erasmus, M. Landman, J.W. Niemantsverdriet and J.C. Swarts, Consequences of electron-density manipulations on the X-ray photoelectron spectroscopic properties of ferrocenyl- $\beta$-diketonato complexes of manganese(III). Structure of $\left[\mathrm{Mn}\left(\mathrm{FcCOCHCOCH}_{3}\right)_{3}\right]$, Inorg Chem., 2016, 55, 1992-2000.

29 R. Gostynski, J. Conradie, E. Erasmus, Significance of the electron-density of molecular fragments on the properties of manganese(III) $\beta$-diketonato complexes: an XPS and DFT study, RSC Adv. $2017,7,27718-27728$.

30 V.V. Nemoshalenko, V.V. Didyk, V.P, Kriskii and A.I. Senekevich, Study of the charge state of atoms in iron, cobalt, and nickel phosphides, Zh. Neorg. Khimii, 1983, 28, 2182-2192.

31 J.A. Connor, L.M.R. Derrick and I.H. Hillier, High energy photoelectron spectroscopy of transition metal complexes. Part 4.-Bis(arene) and related complexes of chromium, manganese and iron, J. Chem. Soc. Faraday Trans., 1974, 70, 941-944.

32 M. Trzebiatowska-Gusowska, A. Gagor, E. Coetsee, E. Erasmus, H.C. Swart and J.C. Swarts, Nano islet formation of formyl- and carboxyferrocene, -ruthenocene, -osmocene and cobaltocenium on amine-functionalized silicon wafers highlighted by crystallographic, AFM and XPS studies, J. Organomet. Chem., 2013, 745, 393-403.

33 Gordy-scale group electronegativities, $\chi_{R}$, are empirical numbers that express the combined tendency of a group of atoms, like $\mathrm{R}=\mathrm{CF}_{3}$ or $\mathrm{CH}_{3}$, to attract electrons (including those in a covalent bond) as a function of the number of valence electrons, $n$, and the covalent radius, $r(\AA)$, of groups as discussed in the following: (a) P.R. Wells, in Progress in Physical Organic Chemistry Vol. 6, John Wiley \& Sons, New York, 1968, p 111-145, and (b) R.E. Kagarise, Relation between the electronegativities of adjacent substitutents and the stretching frequency of the carbonyl group, J. Am. Chem. Soc., 1955, 77, 1377-1379.

34 A.J. Nelson, J.G. Reynnolds and J.W. Roos, Core-level satellites and outer core-level multiplet splitting in Mn model compounds, J. Vac. Sci. Tech., 2000, 18, 1072-1076.

35 L. Ley, S.P. Kowalczyk, F.R. McFreely and D.A. Shirley, Crystal-field effects on the apparent spin-orbit splitting of core and valence levels observed by x-ray photoemission, Phys. Chem. Rev. B, 1974, 10, 4881-4888.

36 B.E. Buitendach, E. Erasmus, J.W. Niemantsverdriet and J.C. Swarts, Properties of manganese(III) ferrocenyl- $\beta$-Diketonato complexes revealed by charge transfer and multiplet splitting in the $\mathrm{Mn} 2 \mathrm{p}$ and $\mathrm{Fe}$ 2p X-ray photoelectron envelopes, Molecules, 2016, 21, 1427-1442.

37 R. Liu, J. Conradie and E. Erasmus, Comparison of X-ray photoelectron spectroscopy multiplet splitting of $\mathrm{Cr} 2 \mathrm{p}$ peaks from chromium tris( $\beta$-diketonates) with chemical effects, J. Electron Spec. Rel. Phenom., 2016, 206, 46-51.

38 W. Chen, Y. Feng, M. Zheng, J. Wu, J. Zhang, X. Gao, J. He and J. Zhang, Homogeneous benzoylation of cellulose in 1-allyl-3methylimidazolium chloride: Hammett correlation, mechanism and regioselectivity, RSC Advances, 2015, 5, 58536-58542.

39 A. Thirumoorthi, D.S. Bhuvaneshwari and K.P. Elango, Preferential solvational effects on the $\mathrm{Cr}(\mathrm{VI})$ oxidation of benzylamines in benzene/2-methylpropan-2-ol mixtures, Int. J. Chem. Kin., 2010, 3, $159-167$.

40 B.J. Stokes, K.J. Richert and T.G. Driver, Examination of the mechanism of Rh2(II)-catalyzed carbazole formation using intramolecular competition experiments, J. Org. Chem., 2009, 74, 6442-6451.

41 P. De Maria, A. Fontana, C. Gasbarri, G. Siani and P. Zanirato, Kinetics of the Z-E isomerization of monosubstituted azobenzenes in polar organic and aqueous micellar solvents, Arkivoc, 2009, viii, 16-29.

42 S. Huang, J.C.S. Wong, A.K.C. Leund, Y.M. Chan, L. Wong, M.R. Fernendez, A.K. Miller, W. Wu, Excellent correlation between substituent constants and pyridinium N-methyl chemical shifts, Tet. Lett., 2009, 50(35), 5018-5020. 


\section{Supplementary material to:}

E. Erasmus,

Electronic Effects of Group Fragments on the XPS of Fe 2p and 3p Photoelectron Lines of Ferrocenyl-containing Chalcones,

S. Afr. J. Chem., 2017, 70, 94-99. 
Electronic effects of group fragments on the XPS of Fe 2p and 3p photoelectron lines of ferrocenyl-containing chalcones

E. Erasmus*

\section{Supplementary information}

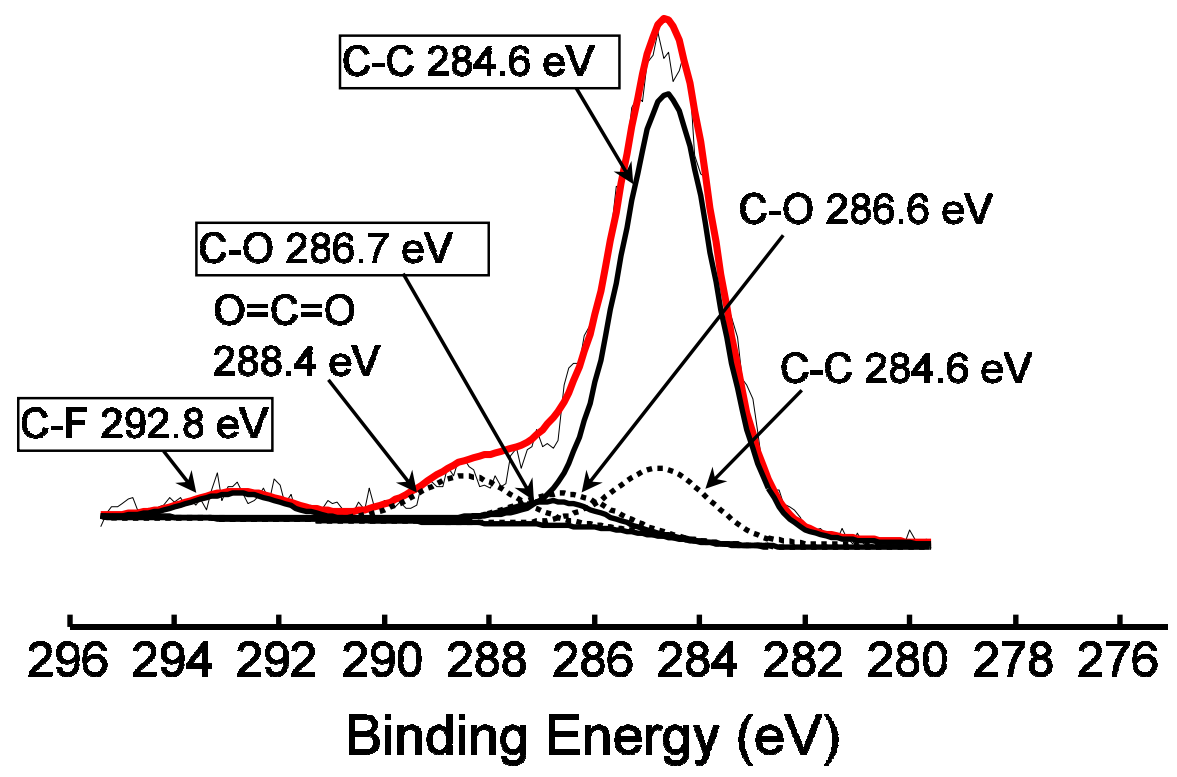

Figure S1. The detail XPS of the C 1s area of 7. The red line represents the total simulated fit, while the solid black line represents the carbon fitted for the ferrocenyl-containing chalcone, 7, and the broken black lines represent the carbon from the adventitious carbon. 